\title{
Multiple acute infarcts in the posterior circulation
}

\author{
Andrea Bernasconi, Julien Bogousslavsky, Claudio Bassetti, Franco Regli
}

\begin{abstract}
Objective-to evaluate clinical, radiological, and prognostic features of patients with multiple acute infarcts in remote arterial territories of the posterior circulation.
\end{abstract}

Design-Data analysis from a prospective acute stroke registry in a community based primary care centre using a standard protocol including MRI and MRA.

Results-In three and a half years, 27 of the 236 patients $(11 \%)$ with posterior circulation stroke had multiple acute infarcts in the posterior circulation as shown by gadolinium enhancement on MRI. Eighteen patients had multiple infratentorial and supratentorial infarcts including the cerebellum and posterior cerebral artery territory, with coexisting brainstem involvement in seven patients. Fourteen patients had a rostral basilar artery syndrome and cerebellar signs; four patients had a visual field defect with cerebellar signs. Causes were vertebral (six) or basilar (four) artery atheromatosis, and cardioembolism (four). Seven patients had multiple acute infarcts in the posterior circulation of the cerebellum and lower brainstem. Brainstem and cerebellar signs were found in most patients (five); aetiologies were small vessel disease (four), cardioembolism (one), and vertebral artery dissection (one). Two patients with large artery atheromatosis had multiple acute infarcts in the posterior circulation in the brainstem and posterior cerebral artery territory. One month after stroke more than $25 \%$ of the patients were dependent or had died. There was no difference in the outcome between the three groups, and recovery was linked to the size of infarcts rather than to a high number of infarcts.

Conclusions-multiple acute infarcts in the posterior circulation usually involve the cerebellum. Simultaneous brainstem and posterior cerebral artery territory infarcts sparing the cerebellum are uncommon. They can be suspected clinically before neuroimaging, mainly when supratentorial and infratentorial infarcts coexist. This may be important, because different patterns of infarction are associated with different causes of stroke.

(F Neurol Neurosurg Psychiatry 1996;60:289-296)
Keywords: acute multiple infarcts; posterior circulation; magnetic resonance imaging

Although most clinical topographic stroke studies have been limited to patients with involvement of single vascular territories, acute infarction may involve more than one territory. ${ }^{1-20}$

Because of its sensitivity, ${ }^{21} \mathrm{MRI}$ may detect multiple infarcts that have been overlooked in previous studies, mainly due to the low yield of CT in infratentorial infarction. ${ }^{82-24}$

We prospectively studied clinical, imaging, aetiological, and functional characteristics of all patients with multiple acute infarcts in the posterior circulation who were included in the Lausanne Stroke Registry ${ }^{25}$ over three and a half years. We used a standard protocol of investigations including MRI and magnetic resonance angiography (MRA).

\section{Methods}

We studied all patients who were admitted to our population based primary care centre over 42 months with a first stroke in the posterior circulation. These patients represented a subsample of 800 patients included consecutively in the Lausanne Stroke Registry. The main criterion for inclusion into the study was the presence of more than one acute infarct involving remote arterial territories in the posterior circulation, shown by gadolinium enhancement on MRI.

The infarcts were demonstrated by high field MRI (Siemens Magnetom SP $63 \quad 1.5$ Tesla) usually conducted within one week and in all patients within 13 days of stroke onset. Studies with MRI included T1, T2, and proton weighted images ( $5 \mathrm{~mm}$ thick slices); contrast images ( $T 1$ sagittal and transverse $5 \mathrm{~mm}$ slices) were obtained after injection of gadolinium. Three dimensional MRA of vertebral and basilar arteries (3D TOF, 64 slices of $0.8-1 \mathrm{~mm}$ ) was also performed in all patients..$^{20}$ Basilar artery, intracranial vertebral arteries, the proximal portion of cerebellar arteries, and the posterior cerebral arteries were studied. The extracranial segment of vertebral arteries was studied from the changes in the opacification of the corresponding vessel on MRA with Doppler ultrasound confirmation.

Posterior circulation infarcts, other parenchymal changes, and relevant arterial lesions were recorded and classified into previously defined categories. ${ }^{1720}$ The nine following topographic categories were considered: 
medulla, pons, cerebellum (posterior inferior/ anterior inferior/superior cerebellar artery territories), midbrain, thalamus (posterior cerebral artery deep territory), occipital (temporal) region (posterior cerebral artery superficial territory), and combined involvement. We assessed the topography of cerebellar infarcts on MRI following previously published templates which are currently used in our department. ${ }^{22}$ Other parenchymal lesions were also recorded, including anterior circulation infarcts, focal areas of hyperintense signal, and diffuse leukoaraiosis. Arterial lesions were classified into seven categories: dolichoectatic vertebral/basilar arteries, vertebral artery stenosis or occlusion, basilar artery stenosis or occlusion, and occlusion of major branches of the basilar artery (including posterior cerebral artery). Acute infarcts were defined as ischaemic lesions greater than an enlarged Virchow-Robin perivascular space (which demonstrates a low signal intensity on $\mathrm{T} 1$ weighted images and a high signal on T2 weighted images) and showing gadolinium enhancement. An uninterrupted lesion visible on two or more neighbouring slices on MRI was considered to be an infarct in a single arterial territory, even if it involved more than one of our nine topographic categories. Thus infarcts involving simultaneously two different contiguous anatomical structures (for example, brainstem plus cerebellum or thalamus plus mesencephalon) but corresponding to a single vascular territory, and infarction overlapping adjacent territories (for example, posterior inferior cerebellar artery and superior cerebellar artery) were considered a single lesion. Bilateral infarct in the thalamoperforate territory (paramedian, thalamic-subthalamic artery) from the P1 segment of the posterior cerebral artery was also classified as a single lesion, ${ }^{26}$ as was infarction in the posterior cerebral artery territory involving the superficial (occipital-temporal) and deep (mesencephalothalamic) region. Thus multiple acute infarcts in the posterior circulation corresponded to involvement of two or more of the three main sequential segments of the posterior circulation defined in the New England Medical Center classification ${ }^{17}{ }^{27}$ : proximal (medulla and posterior inferior cerebellar artery cerebellum fed by the intracranial vertebral arteries and their branches); middle (pons, lower midbrain, and anterior inferior cerebellar artery cerebellum fed by basilar artery and branches); and distal (upper midbrain, thalamus, superior cerebellar artery cerebellum and temporal and occipital lobes fed by the distal basilar artery and superior cerebellar artery, penetrating and posterior cerebral artery branches). Infarcts with a largest diameter $\leqslant 15 \mathrm{~mm}$ were classified as small.

Neurological and neuropsychological features were assessed by at least two of the authors including a senior neurologist (JB) within five days of stroke. We analysed clinical features and information about risk factors defined following published guidelines ${ }^{25}$ including hypertension (blood pressure higher than $160 / 90 \mathrm{~mm} \mathrm{Hg}$ at least twice before stroke), diabetes mellitus (fasting blood glucose concentrations above $6.0 \mathrm{mmol} / \mathrm{l}$ known to exist before stroke), regular cigarette smoking, hypercholesterolaemia (fasting blood cholesterol above $6.5 \mathrm{mmol} / \mathrm{l}$ ), venous packed cell volume, heart disease (including angina pectoris, old myocardial infarct, chronic nonvalvar atrial fibrillation), and previous transient ischaemic attack(s). Apart from MRI and MRA, systematic investigations included brain CT on admission, three lead ECG monitoring for at least 24 hours after admission, 12 lead ECG, standard blood tests, Doppler ultrasonography with frequency spectral analysis, and B-mode echotomography of the origin of the carotid arteries and vertebral arteries. Additional catheter cerebral angiography using the Seldinger method was performed in two patients, and transthoracic/transoesophageal echocardiography was performed in 20 selected patients with presumed cardioembolism.

We considered the following potential causes of stroke: (a) in situ atherosclerosis or artery to artery embolism (large artery disease) in patients with risk factors who had a stenosis of at least $70 \%$ of the lumen diameter in the appropriate large artery as shown by three dimensional images on MRA or conventional angiography using the NASCET method; (b) small artery disease ${ }^{20}$ was presumed in patients with longstanding hypertension or diabetes mellitus (in the absence of potential arterial or cardiac sources of emboli) and a small ( $\leqslant 15 \mathrm{~mm}$ ) infarct limited to the territory of deep perforators; (c) potential cardiac sources of embolism (mainly non-valvar atrial fibrillation, left ventricular akinetic segment, and other less common sources) were considered according to previously defined crite$\mathrm{ria}^{425}$; (d) other and undetermined. The evolution within the first four weeks after stroke was recorded in all patients.

\section{Results}

Twenty seven (11\%) of 236 patients with vertebrobasilar ischaemic stroke had multiple acute infarcts in the posterior circulation. There were nine women (33\%) and 18 men $(67 \%)$. The median age was 66 (range 32 to 87) years.

\section{GENERAL AND NEUROLOGICAL VASCULAR} FEATURES

Nine patients (26\%) had a history of ischaemic heart disease and one patient (No 26) had non-valvar atrial fibrillation (table 1). Eleven patients $(41 \%)$ had hypertension, six patients $(22 \%)$ smoked cigarettes regularly, four patients (15\%) had hypercholesterolaemia, four patients (15\%) had diabetes, 12 patients $(44 \%)$ had multiple risk factors, and six patients $(22 \%)$ had none of these risk factors. Two patients $(8 \%)$ had a patent foramen ovale. Overall, age, sex, and risk profiles were similar to those of the patients from the Lausanne Stroke Registry in general. ${ }^{25}$ Three patients $(11 \%)$ had had transient ischaemic attack(s) (five months, one week, four years 
before stroke) in the posterior circulation. ${ }^{28}$ Sixteen patients $(59 \%)$ had a sudden nonprogressive onset of symptoms, whereas stroke was progressive in $11(44 \%)$ patients (over 2-24 hours in five patients, over more than 24 hours to 15 days in six patients).

TOPOGRAPHY OF INFARCTS (TABLES $1,2,3$, AND 4)

Our patients had from two to seven infarcts (median 3.6) including cerebellum (25), brainstem (17), occipital lobe (13), or thalamus (11). Cerebellar infarcts were bilateral in $80 \%$ of the patients $(20 / 25)$, brainstem infarcts occurred in $24 \%(4 / 17)$ and occipitothalamic infarcts were found in $8 \%$ of patients $(2 / 24)$. In the 25 patients with cerebellar infarction the following vascular territories were involved: posterior inferior cerebellar artery in 22 patients (Nos 1-12, 14, 15, $18-20,22-25,27$ ), bilaterally in 10 ; superior cerebellar artery in 15 patients (Nos $1,3,5,6$, $10-16,18,23,24,26$ ), bilaterally in five; anterior inferior cerebellar artery in five patients (Nos $4,5,10,12,24)$. In patients with brainstem infarction, the territory of the paramedian and circumferential arteries was involved in 13 patients (Nos $1,4,5,7,9,14,17-19$, $21,22,23,25)$, and the territory of the short circumferential arteries from the P2 segment of the posterior cerebral artery was involved in four patients (Nos 10,11, 17, 24). The occipital lobe was affected in 13 patients (Nos $1,2,3$, $6,8,12-14,18,21,23,26,27)$, bilaterally in only one (No 6). The thalamus was involved in 11 patients (Nos $1-3,10,11,12,15-18$, 20 ), bilaterally in two (Nos 16,17) (in six patients the infarct was localised to the territory of the thalamogeniculate arteries ${ }^{26}$ (inferolateral pedicle ${ }^{29}$ ), in five patients to the paramedian territory ${ }^{29}$ (thalamic-subthalamic arterie $\left.{ }^{26}\right)$ ). No patient had a medullary infarct.

We identified three clinicotopographic patterns of multiple acute posterior circulation infarcts (tables 1,2, and 3):

(1) Multiple infratentorial and supratentorial infarcts of cerebellum and posterior cerebral artery (or proximal and/or middle + distal multiple acute infarcts in the posterior circulation (Nos 17,27)): 18 (67\%)

Seven patients $(39 \%)$ also had a brainstem infarct (table 1). Most of the patients $(78 \%=14 / 18)$ clinically had a rostral basilar artery syndrome ${ }^{730}$ (including hemianopia in seven patients) and cerebellar signs; four other patients had a visual field defect and cerebellar signs (table 4). A history of ischaemic heart disease (39\%) and hypertension (33\%) was common. Contrast angiography was normal in one patient (No 15) without risk factors. The presumed cause of stroke was large artery disease in nine patients: focal (two) atheromatosis of the basilar artery; multifocal atheromatosis (one), and focal stenosis (one) or occlusion (two) of one intracranial vertebral artery. One patient (No 8) had a tandem intracranial atheromatous stenosis with diffuse narrowing of the basilar artery associated with a stenosis of the posterior cerebral artery. One patient (No 11) had an occlusion of the proximal right vertebral artery and a distal focal stenosis of the left vertebral artery; one patient (No 23) had coexisting focal stenosis of the basilar artery and left vertebral artery. Cardioembolism was the likely aetiology in five patients with a history of myocardial infarct with akinetic left ventricular segment, and non-valvar atrial fibrillation. A 48 year old man (No 12) died two days after stroke: he had developed headache, vomiting, left sensory-motor hemiparesis, and ataxia, with rapid coma. Brain MRI showed multiple, large and bilateral infarcts in all three cerebellar and both posterior cerebral artery territories. Brain MRA suggested an occlusion in the distal portion of the basilar artery and left posterior inferior cerebellar artery, with otherwise intact arteries. Although transthoracic echocardiography was normal, a cardioembolic mechanism was suspected. Aetiology remained unknown in three patients, and uncertain in two patients with only a patent foramen ovale (Nos 24, 27). One month after stroke 13 patients $(72 \%)$ were independent, and four (22\%) were still dependent.

(2) Multiple infratentorial infarcts of cerebellum and lower brainstem (or proximal + middle multiple acute infarcts in the posterior circulation (Nos 17,27)):seven (26\%)

These patients showed brainstem signs sometimes combined with cerebellar ataxia (table 4). Presumed aetiology was hypertensive small artery disease in four patients ( $57 \%)$. A 51 year old patient (No 4) had IgM anticardiolipin antibodies without any other potential cause of stroke. Another patient (No 5) had a proximal occlusion of the right vertebral artery related to a subintimal dissection detected on conventional angiography. The likely cause of stroke was cardioembolism in a 55 year old woman with coronary heart disease and an akinetic left ventricular segment. All but one patient was independent one month after stroke (table 2).

(3) Multiple infarcts of brainstem and posterior cerebral artery (or proximal + middle multiple acute infarcts in the posterior circulation (Nos 17,27)): two (7\%).

Only two patients had multiple supratentorial and infratentorial infarcts including pons and both posterior cerebral artery territories, but sparing the cerebellum (table 3 ). These patients had brainstem signs (table 4); MRA showed basilar artery or vertebral artery atheromatosis in both patients. In patient No 17 there was an extension of a thrombus from the intracranial vertebral artery to the proximal basilar artery.

\section{CONCOMITANT VASCULAR DISEASES}

No patient had had a recent ischaemic event in the anterior circulation, and none had an old infarct in the posterior circulation. A carotid stenosis was found in one patient, who had had an episode of amaurosis fugax six years before the present stroke (No 10). An asymptomatic carotid stenosis was detected in four patients, including an intracranial stenosis in one patient (No 8). Nine patients (Nos 3-9, 
Table 1 Infratentorial and supratentorial multiple acute infarcts in the posterior circulation (cerebellum, posterior cerebral artery and brainstem; proximal and/or middle + distal (Nos 17, 27))

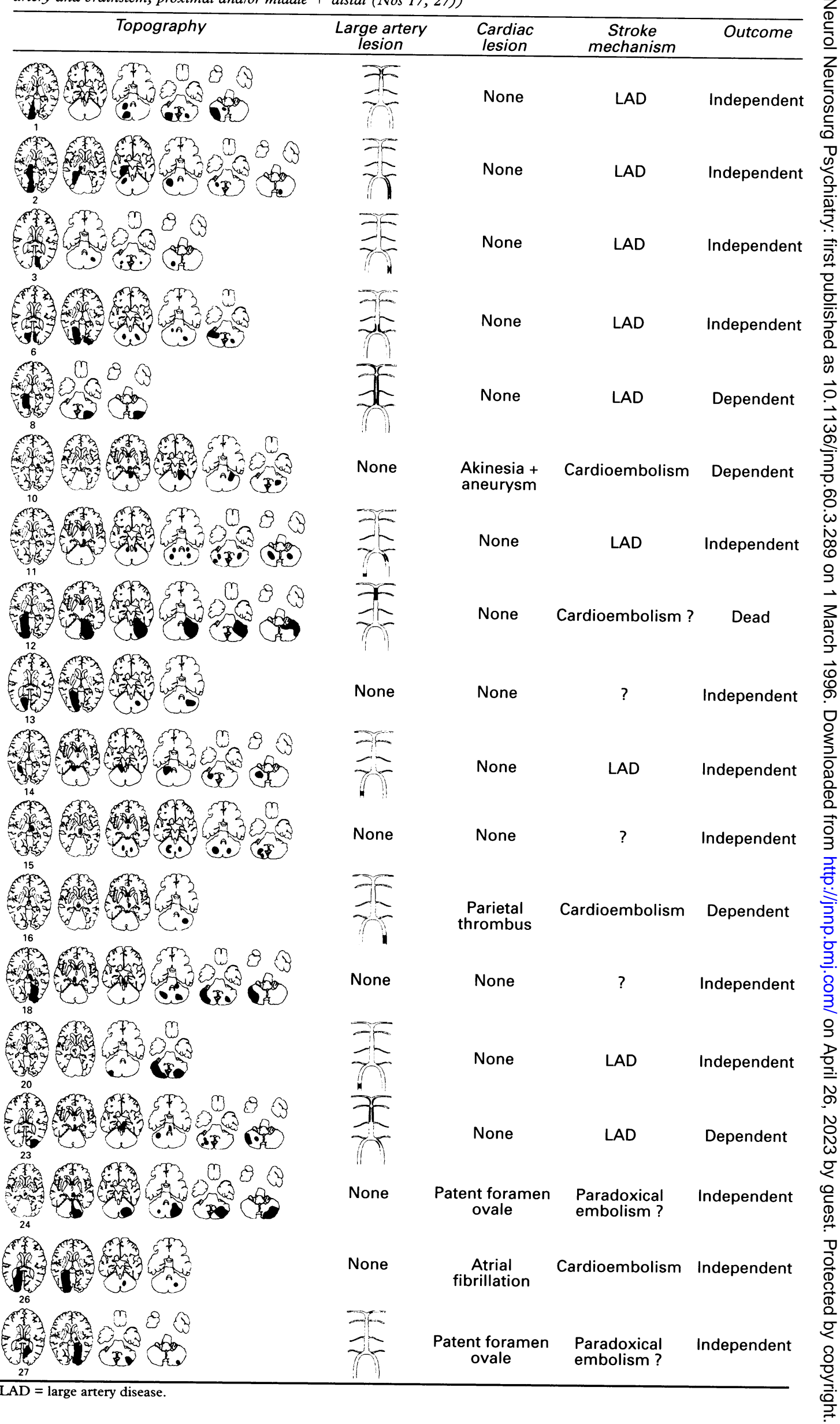


Table 2 Cerebellum and lower brainstem multiple acute infarcts in the posterior circulation (proximal + middle (Nos 17, 27))

\begin{tabular}{|c|c|c|c|c|}
\hline Topography & $\begin{array}{c}\text { Large artery } \\
\text { lesion }\end{array}$ & $\begin{array}{l}\text { Cardiac } \\
\text { lesion }\end{array}$ & $\begin{array}{c}\text { Stroke } \\
\text { mechanism }\end{array}$ & Outcome \\
\hline 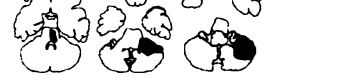 & None & None & $\begin{array}{l}\text { Anticardiolipin } \\
\text { antibodies }\end{array}$ & Independent \\
\hline & the & None & $\begin{array}{c}\text { LAD } \\
\text { (dissection) }\end{array}$ & Dependent \\
\hline & None & None & SAD & Independent \\
\hline & None & None & SAD & Independent \\
\hline$w_{\gamma}$ & None & None & SAD & Independent \\
\hline 2 & None & None & SAD & Independent \\
\hline 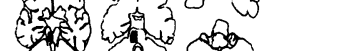 & None & Akinesia & Cardioembolism & Independent \\
\hline
\end{tabular}

11, 20-22) had leukoaraiosis. Two patients (Nos 10, 16) with multiple infratentorial and supratentorial infarcts, possibly of cardioembolic origin, also had a dolichoectatic basilar artery. We found no patient with arteritis or another angiopathy. One patient (No 8) with peripheral arteriopathy and one patient (No 11) with aortocoronary bypass were under anticoagulant therapy at the onset of stroke. No patient was under antiaggregant therapy at the time of the index stroke.

\section{EVOLUTION}

Haemorrhagic transformation of infarct was only seen in one non-anticoagulated patient who had three infarcts (No 10). One patient (No 5) with bilateral large cerebellar infarcts and a pontine infarct developed a compression of the fourth ventricle with hydrocephalus. $\mathrm{He}$ improved after external ventricular drainage. One month after stroke, 20 patients (74\%) were independent, six were dependent, and one had died. This contrasted with only 19 (9\%) of the 209 patients with one single infarct being dependent at one month
$(\mathrm{P}<0.01)$. Of 20 patients (Nos $1,2,4,5,6$, $8,10-18,20,23,24,26,27 ; 74 \%$ ) with large infarcts $(>3 \mathrm{~cm},>2$ slices on MRI), six ( $30 \%$ ) had a poor functional outcome and one died. On the other hand, 12 of 18 patients (67\%) with more than two infarcts were independent one month after stroke.

\section{Discussion}

Acute multiple infarcts in the posterior circulation were not uncommon, as they represented over $11 \%$ of first ever acute ischaemic stroke in this territory, but we believe that they have been commonly overlooked, especially without systematic MRI. This is by contrast with the absence of a specific study devoted to that important issue. Barkhof and Valk ${ }^{31}$ studied clinicoradiological correlations in four patients with multiple lesions in the vertebrobasilar system detected on MRI and "top of the basilar" syndrome, ${ }^{3}$ but angiography was not performed and the cause of infarct was not considered. Among 14 patients with an infarct in the superior cerebellar artery terri-

Table 3 Brainstem and posterior cerebral artery territory multiple acute infarcts in the posterior circulation (proximal + middle (Nos 17, 27))

\begin{tabular}{llll} 
Topography & $\begin{array}{c}\text { Large artery } \\
\text { lesion }\end{array}$ & $\begin{array}{c}\text { Cardiac } \\
\text { lesion }\end{array}$ & $\begin{array}{c}\text { Stroke } \\
\text { mechanism }\end{array}$ \\
\hline Outcome
\end{tabular}

$\mathrm{LAD}=$ large artery disease. 
Table 4 Topography, clinical features, and outcome of 27 patients with multiple acute infarcts in the posterior circulation

\begin{tabular}{|c|c|c|c|c|c|}
\hline & Vascular territory & No & $T L A$ & Onset & Symptoms \\
\hline \multicolumn{6}{|c|}{ Infratentorial and supratentorial MAPCI (cerebellum, PCA and brainstem) } \\
\hline 1 & PICA, $1+m ;$ SCA, $1+m ; p ;$ PCA: Th (il) & $7, \mathrm{~b}$ & \multirow{4}{*}{,$+ \mathrm{s}$} & s & HH, CNP (VII), limb and trunk ataxia, nystagmus \\
\hline 2 & PICA, $1+$ m; SCA, l; Th (il); PCA & $4, b$ & & s & $\begin{array}{l}\mathrm{HH} \text {, nystagmus, dysarthria, } \mathrm{M}+\mathrm{S}(\mathrm{f}, \mathrm{u}, \mathrm{l}) \text {, limb and trunk } \\
\text { ataxia, asterixis }\end{array}$ \\
\hline 3 & PICA, m; SCA, m; PCA & $4, \mathrm{~b}$ & & $\mathrm{p}$ & HH, vertical gaze palsy, dysarthria, limb ataxia \\
\hline 6 & $\mathrm{PICA}, \mathrm{l}+\mathrm{m} ; \mathrm{SCA}, \mathrm{l}+\mathrm{m} ; \mathrm{PCA}$ & $6, \mathrm{~b}$ & & $\mathrm{p}$ & $\begin{array}{l}\text { HH, nystagmus, dysarthria, limb ataxia, NPsy } \\
\text { (asimultagnosia, visual hallucinations, achromatopsia) }\end{array}$ \\
\hline 8 & PICA, m; PCA & $2, b$ & \multirow{3}{*}{,+ 0} & $\mathbf{s}$ & $\mathrm{HH}$, vertical gaze palsy, limb and trunk ataxia \\
\hline 10 & PICA, l; AICA; SCA, 1; m (sc); Th (il) & $3, \mathrm{u}$ & & $\mathrm{s}$ & $\begin{array}{l}\text { Somnolence, vertical gaze palsy, CNP (III), dysphagia, } \\
\text { dysarthria, } M(f, u, 1) \text {, limb ataxia }\end{array}$ \\
\hline 11 & PICA, l + m; SCA, 1 + m; m (sc); Th (il) & $6, \mathrm{~b}$ & & $\mathbf{p}$ & $\begin{array}{l}\text { CPN (III), dysarthria, limb and trunk ataxia, NPsy } \\
\text { (amnesia, apathy, confusion) }\end{array}$ \\
\hline 12 & PICA, 1; AICA; SCA, 1 + m; PCA; Th (il) & \multicolumn{2}{|l|}{$3, \mathrm{~b}$} & $\mathrm{p}$ & $\begin{array}{l}\text { Somnolence/coma, nystagmus, } M+S(u, l) \text {, limb and trunk } \\
\text { ataxia }\end{array}$ \\
\hline 13 & SCA, $1+\mathrm{m} ; \mathrm{PCA}$ & \multirow{3}{*}{\multicolumn{2}{|c|}{$\begin{array}{l}2, \mathrm{~b} \\
4, \mathrm{~b} \\
4, \mathrm{~b}\end{array}$}} & $\mathbf{s}$ & $\mathrm{HH}$, limb and trunk ataxia \\
\hline 14 & PICÁ, l; SCA, l; p; PCA & & & $\mathrm{s}$ & $\mathrm{HH}$, dysarthria, limb and trunk ataxia \\
\hline 15 & PICA, l + m; SCA, m; Th (pm) & & & $\mathrm{p}$ & $\begin{array}{l}\text { Stupor, } M \text { (f, u, l), NPsy (apathy, subcortical aphasia), } \\
\text { asterixis, dysarthria }\end{array}$ \\
\hline 16 & $\mathrm{SCA}, \mathrm{m} ; \mathrm{Th}(\mathrm{pm})$ & \multicolumn{2}{|l|}{$2, \mathrm{~b}$} & s & $\begin{array}{l}\text { Stupor, vertical gaze palsy, CNP (III, IV), limb and trunk } \\
\text { ataxia, } M(u) \text {, NPsy (dementia) }\end{array}$ \\
\hline 18 & PICA, l; SCA, m + l; p; PCA; Th (pm) & \multicolumn{2}{|l|}{$7, \mathrm{~b}$} & $\mathbf{p}$ & $\begin{array}{l}\text { HH, Horner's syndrome, } M(u, l) \text {, dysarthria, NPsy } \\
\text { (confusion, apathy, amnesia) }\end{array}$ \\
\hline 20 & PICA, $1+\mathrm{m} ; \mathrm{Th}(\mathrm{pm})$ & \multicolumn{2}{|l|}{$3, \mathrm{~b}$} & s & $\begin{array}{l}\text { Somnolence vertical gaze palsy, } M(f, u, l), \text { NPsy } \\
\text { (confusion), dysarthria }\end{array}$ \\
\hline 23 & PICA, $1+$ m; SCA, $1 ;$ p; PCA & \multicolumn{2}{|l|}{$4, \mathrm{~b}$} & s & $\begin{array}{l}\mathrm{HH} \text {, "one and a half" palsy, CNP (V, VII), dysphagia, } \\
\text { dysarthria, } M+S(f, u, 1) \text {, limb ataxia }\end{array}$ \\
\hline 24 & PICA, 1 + m; SCA; AICA; m (sc) & \multicolumn{2}{|l|}{$3, \mathrm{~b}$} & s & $\begin{array}{l}\text { Skew deviation, } M \text { (u), trunk ataxia, dysarthria, NPsy } \\
\text { (apathy, emotional lability, apraxia) }\end{array}$ \\
\hline 26 & SCA, m: PCA & \multirow{2}{*}{\multicolumn{2}{|c|}{$\begin{array}{l}2, \mathrm{~b} \\
3, \mathrm{u}\end{array}$}} & $\mathrm{p}$ & $\mathrm{HH}$, dyssarthria, limb and trunk ataxia \\
\hline 27 & PICÁ, l; PCA; Th (il) & & & s & $\begin{array}{l}\text { HH, trunk ataxia, NPsy (alexia, achromatopsia, amnesia), } \mathrm{S} \\
(\mathrm{f}, \mathrm{u})\end{array}$ \\
\hline \multicolumn{6}{|c|}{ Cerebellum and lower brainstem $M A P C I$} \\
\hline 4 & PICA, 1; AICA; p & \multicolumn{2}{|l|}{$2, \mathrm{u}$} & $\mathrm{p}$ & $\begin{array}{l}\text { Saccadic horizontal pursuit, nystagmus, CPN (VIII, } \\
\text { cochlear), } M(f, u, l) \text {, limb and trunk ataxia }\end{array}$ \\
\hline 5 & PICA, $1+\mathrm{m} ;$ AICA; $p$ & $3, \mathrm{~b}$ &,$+ \mathrm{s}$ & $\mathbf{p}$ & $\begin{array}{l}\text { Somnolence/coma, nystagmus, CNP (V, VI, VII), } \\
\text { dysarthria, limb and trunk ataxia, } S(f, u)\end{array}$ \\
\hline 7 & PICA, $1+\mathrm{m} ; \mathrm{p}$ & \multicolumn{2}{|l|}{$3, \mathrm{~b}$} & s & $\begin{array}{l}\text { Saccadic horizontal pursuit, CNP (VII), limb and trunk } \\
\text { ataxia }\end{array}$ \\
\hline 9 & PICA, m; p & \multirow{2}{*}{\multicolumn{2}{|c|}{$\begin{array}{l}2, \mathrm{~b} \\
2, \mathrm{~b}\end{array}$}} & s & Dysarthria, M (ataxic hemiparesis) \\
\hline 19 & PICA, $1 ; \mathrm{p}$ & & & $\mathrm{p}$ & Dysarthria, $M(f, u, l)$ \\
\hline 22 & PICA, $m ; p$ & \multicolumn{2}{|l|}{$2, \mathrm{u}$} & $\mathrm{s}$ & Saccadic horizontal pursuit, dysarthria, $M(f, u, l)$ \\
\hline 25 & PICA, $1 ; p$ & \multicolumn{2}{|l|}{$2, \mathrm{u}$} & s & $\mathrm{CNP}(\mathrm{V}, \mathrm{VI})$, trunk ataxia \\
\hline \multicolumn{6}{|c|}{ Brainstem and $P C A$ territory $M A P C I$} \\
\hline 17 & $\mathrm{p} ; \mathrm{m}(\mathrm{sc}) ; \mathrm{Th}(\mathrm{tt}, \mathrm{pm})$ & $5, \mathrm{~b}$ &,$+ \mathrm{s}$ & $\mathrm{p}$ & $\begin{array}{l}\text { Vertical gaze palsy, Horner's syndrome, pseudo-VI, M } \\
\text { (ataxic hemiparesis), NPsy (visual and auditive } \\
\text { hallucinations), nystagmus }\end{array}$ \\
\hline 21 & p; PCA & $3, \mathrm{~b}$ & & s & Dysarthria, $\mathbf{M}$ (ataxic hemiparesis) \\
\hline
\end{tabular}

TIA = transient ischaemic attack; No $=$ number of infarcts; $u / b=$ unilateral, bilateral; so = same/other vascular territory; NPsy = neurological disturbance; $M / S(f, u, l)=$ motor weakness $(M) /$ sensory disturbance (face (f), upper (u), lower (l) limb); $\mathrm{NPsy}=$ neurological disturbance; $M / S(\mathrm{~S}, \mathrm{u}, 1)=$ motor weakness $(\mathrm{M}) / \mathrm{s}$
$\mathrm{HH}=$ homonymous hemianopia; $\mathrm{CNP}=$ cranial nerve palsy (III-XII).

$\mathrm{HH}=$ homonymous hemianopia; $\mathrm{CNP}=$ cranial nerve palsy (III-XII).
Vascular territories-Cerebellum: PICA, $\mathrm{m} / \mathrm{=}$ - posterior inferior cerebellar artery, media/lateral branch; AICA = anterior inferio Vascular territories-Cerebellum: PICA, $\mathrm{m} / \mathrm{l}=$ posterior inferior cerebellar artery, media/lateral branch; AICA $=$ anterior inferio
cerebellar artery; SCA $\mathrm{m} / \mathrm{l}=$ superior cerebellar artery, media/lateral branch. Thalamus: th, $\mathrm{t} t=$ thalamotuberal artery (polar artery); th, $\mathrm{pm}=$ paramedian artery (thalamic-subthalamic artery), th, il = inferolateral artery (thalamogeniculate artery). Occipita lobe: PCA = cortical branches of posterior cerebral artery. Mesencephalon: $\mathrm{m}$, sc = short circumferential arteries from PCA (P2 segment). Pons: $p=$ paramedian, short and long circumferential arteries.

tory on MRI or CT, Struck et $a l^{13}$ reported that 11 had associated infarcts involving other cerebellar, brainstem, and supratentorial territories, but the number of patients without an MRI was not specified. Caplan et al ${ }^{17}$ reported 10 patients with occlusive disease of the proximal vertebral artery and embolism to the posterior circulation: in five subjects MRI showed supratentorial and infratentorial infarcts involving distinct territories. Tettenborn $e t a l^{32}$ reported that of 22 patients with postoperative brainstem and cerebellar infarcts, 10 had multiple infarcts in the posterior circulation. However, these studies did not discuss the topographic, clinical, and prognostic features associated with multiple infarcts. More recently, two reports emphasised that multifocal brainstem ${ }^{33}$ or cerebellar ${ }^{27}$ infarction has been largely overlooked, but without a systematic study of acute multiple posterior circulation infarcts.

Most of our patients (93\%) had a cerebellar component of acute multiple posterior circulation infarcts, often bilateral, which involved the posterior inferior cerebellar artery territory more often than in reported series of "pure" cerebellar infarcts. $.^{22} 34-36$ A supratentorial component of multiple acute posterior circulation infarcts was present in $90 \%$ of the patients, and brainstem infarction in two thirds.

The main clinical presentation in our 20 patients with acute multiple supratentorial and infratentorial infarcts (groups 1 and 3) was a partial and reversible rostral basilar artery syndrome ${ }^{3730}$ in all but one patient, with cerebellar signs and a visual field defect in about half of the patients. No patient had clinical evidence for involvement of only one single vascular territory and none of those with a presumed small artery disease (group 2) had a lacunar syndrome. ${ }^{37}$

Stroke was seldom preceded by transient ischaemic attack compared with other posterior circulation infarcts $\left(18 \%,{ }^{38} 23 \%,{ }^{39} 57 \%{ }^{40}\right)$. Stroke onset was non-progressive in about two thirds of the patients, without significant difference between the aetiological subgroups (artery to artery embolism, cardioembolism, local thrombosis, small artery disease). This suggests that infarcts mostly came on simultaneously. 
No particular risk factor correlated with a poor outcome. There was no difference in the outcome between patients with multiple infratentorial and supratentorial infarcts including the posterior cerebral artery, patients with multiple infratentorial infarcts of the cerebellum and brainstem, and the two patients with multiple infarcts of the brain stem and posterior cerebral artery territory. Nevertheless, multiple acute posterior circulation infarcts were clearly associated with a worse prognosis than single infarcts in the posterior circulation, as $26 \% v 9 \%$ were dead or dependent one month after stroke. However, regardless of distribution of the infarcts, $75 \%$ of our patients with multiple acute infarcts in the posterior circulation were functionally independent one month after stroke. Moreover, there was the same proportion of patients with a good outcome in the groups with either more or less than five infarcts. On the other hand, the patients with large infarcts had a poorer evolution, suggesting that size rather than a large number of infarcts correlates with a poor outcome.

Besides atheroma and embolism, multiple infarction may be related to angiopathies (isolated angiitis, amyloid angiopathy, infectious arteritis, polyarteritis nodosa, Wegener's granulomatosis, giant cell arteritis, Behçet's disease, hypersensitivity vasculitis), coagulopathies, and familial conditions (CADASIL, MELAS), ${ }^{41}{ }^{42}$ but none of our patients had these conditions. Atheromatosis of the large arteries was the most frequent presumed cause of infarct in our series (4\%, table 1$)$, independently of the topography of the lesions. This is not surprising as there was a preponderance of elderly men. Several studies showed that occlusion of rostral basilar territory branches (posterior cerebral artery, distal basilar artery, and superior cerebellar artery) ${ }^{434}$ and intracranial vertebral artery/posterior inferior cerebellar artery is usually embolic, ${ }^{1745}$ intrinsic atherosclerotic disease being more uncommon. ${ }^{46}$ As previously underlined in single infarction in the posterior circulation, 57174447 the proximal segment of the vertebral artery was also suspected to be the embolic source in most of our patients with supratentorial and infratentorial infarcts, suggesting that extracranial vertebral artery disease may play an important part in posterior circulation stroke. On the other hand, no "preferential" localisation $^{40}$ of atheromatosis along the basilar artery was found in our patients, and none of them showed a midbasilar occlusion, which may sometimes be associated with a benign clinical course. ${ }^{4849}$ Atheromatosis may also occlude the origin of vertebral artery and basilar artery branches, particularly involving the smaller penetrating vessels rather than larger branches (cerebellar or anterior spinal arteries). ${ }^{46}$ Small artery disease was uncommon $(15 \%)$ in our patients, although it was relatively more frequent in the patients with multiple, small infarcts $(60 \%)$.

The frequency, location, and severity of carotid atheroma in patients with vertebrobasilar occlusive disease is variable $\left(40 \%,{ }^{1}\right.$ $\left.54 \%{ }^{50}\right)$. We did not find a correlation between posterior circulation and carotid artery atheroma, suggesting that it may develop independently in each of these locations.

Nearly $20 \%$ of our patients had a potential cardiac source of embolism. ${ }^{14}$ This seems similar to what has been reported for ischaemic stroke in general, ${ }^{14} 5152$ including unselected patients with posterior circulation infarct. ${ }^{20}$ Indeed cerebellar and posterior cerebral artery territory infarcts are commonly due to cardiogenic embolism. ${ }^{22} 2547$ In $15 \%$ of our patients, the cause of stroke remained unknown. However, transoesophageal echocardiography was performed in only a few patients and atherosclerotic plaques in the aortic $\operatorname{arch}^{5354}$ were not ruled out.

Overall, our findings suggest that embolism, from an arterial or a cardiac source, is the main aetiology of multiple acute infarcts in the posterior circulation. Whether embolism causes multiple territory infarction by proximal occlusion of major vessels with distal haemodynamic infarction, or it is the result of multiple emboli or a single embolus breaking up and dispersing into different sites is not clear from our study.

Our findings emphasise the heterogeneity of clinical, topographic, and aetiological aspects of multiple acute posterior circulation infarcts. This suggests that early recognition of these types of infarct may have implications for emergency therapy options in the acute phase of stroke, including acute stroke trials assessing fibrinolytic or anti-ischaemic drugs.

1 Castaigne P, Lhermitte F, Gautier J, Escourolle R Derouesné C, der Agopian $P$, et al. Arterial occlusion in the vertebro-basilar system. Brain 1973;96:133-54.

2 Caplan L. Bilateral distal vertebral artery occlusion Neurology 1983;33:552-8.

3 Caplan L. "Top of the basilar" syndrome. Neurology 1980;30:72-9.

4 Graff-Radford N, Damasio H, Yamada T, Elsinger PJ, Damasio AR. Nonhaemorrhagic thalamic infarction clinical, neuropsychological and electrophysiological findings in four anatomical groups defined by computerized tomography. Brain 1985;108:485-516.

5 Koroshetz W, Ropper A. Artery-to-artery embolism causing stroke in the posterior circulation. Neurology 1987 ; 37:292-6.

6 Amarenco P, Hauw J, Hénin D, Duyckaerts C, Roulet E, Laplane $\mathrm{D}$, et al. Les infarctus du territoire de l'artère cérébelleuse postéro-inférieure. Etude clinico-

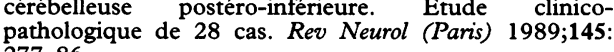

7 Mehler $M$. The rostral basilar artery syndrome. Diagnosis, etiology, prognosis. Neurology 1989;39:9-16.

8 Levine S, Quint D, Pessin M, Boulos RS, Welch KMA Intraluminal clot in the vertebrobasilar circulation: clinical and radiologic features. Neurology 1989;39:515-22.

9 Amarenco P, Hauw J. Cerebellar infarction in the territory of anterior and inferior cerebellar artery. A clinicopathological study of 20 cases. Brain 1990;113:139-55.

10 Amarenco $P$, Hauw J. Cerebellar infarction in the territory of the superior cerebellar artery: a clinicopathologic study of 33 cases. Neurology 1990;40:1383-90.

11 Chambers B, Brooder R, Donnan A. Proximal posterio cerebral artery occlusion simulating middle cerebral cerebral artery occlusion simulating midd

12 Amarenco P. The spectrum of cerebellar infarctions. Neurology 1991;41:73-979.

13 Struck L, Biller J, Bruno A, Neiman RF, Loftus CM, Yuh WTC, et al. Superior cerebellar artery territory infarction. Cerebrovasc Dis 1991;1:71-5.

14 Bogousslavsky J, Cachin C, Regli F, Despland PA, Van Melle G, Kappenberger L. Cardiac sources of embolism and cerebral infarction: clinical consequences and vascular concomitants: the Lausanne Stroke Registry. Neurology 1991;41:855-9.

15 Caplan L, Tettenborn B. Vertebrobasilar occlusive disease: review of selected aspects. 1. Spontaneous dissection of extracranial and intracranial posterior circulation arteries. Cerebrovasc Dis 1992;2:256-65.

16 Fisher M, Sotak C, Minematsu K, Li L. New magnetic resonance techniques for evaluating cerebrovascular disease. Ann Neurol 1992;32:115-22. 
17 Caplan L, Amarenco P, Rosengart A, Lafranchise EF, Teal PA, Belkin M, et al. Embolism from vertebra artery origin occlusive disease. Neurology 1992;42.

18 Bogousslavsky J, Fox A, Barnett H, Hachinski VC, Vinitsk S, Carey LS. Clinico-topographic correlation of smal vertebrobasilar infarct using magnetic resonance imaging. Stroke 1986;17:929-38.

19 Fisher CM. The posterior cerebral artery syndrome. Can $\mathcal{F}$ Neurol Sci 1986;13:232-9.

20 Bogousslavsky J, Regli F, Maeder P, et al. The etiology of posterior circulation infarcts: a prospective study using magnetic resonance angiography. Neurology 1993;43: 1528-33.

21 Daniels DL, Haughton VM, Naidich TP. Cranial and spinal magnetic resonance imaging. An atlas and guide. New York: magnetic resonance ima
Raven Press, 1987.

22 Barth A, Bogousslavsky J, Regli F. The clinical and topographic spectrum of cerebellar infarcts: a clinical-mag netic resonance imaging correlation study. Ann Neurol 1993;33:451-6.

23 Tatemichi TK, Steinke W, Duncan C, Bello JA, Odel JG Behreus MM, et al. Paramedian thalamopeduncular infarction: clinical syndromes and magnetic resonance imaging. Ann Neurol 1992;32:162-71.

24 Amarenco P, Kase CS, Rosengart A, Pessin S, Bousser MG, Caplan LR. Very small (border zone) cerebellar infarcts: distribution, causes, mechanisms and clinical features. Brain 1993;116:161-86.

25 Bogousslavsky J, Van Melle G, Regli F. The Lausanne Stroke Registry: analysis of 1,000 consecutive patients with first stroke. Stroke 1988;19:1083-92.

26 Bogousslavsky J, Caplan LR. Vertebrobasilar occlusive disease: review of selected aspects. 3. Thalamic Infarcts. Cerebrovasc Dis 1993;3:193-205.

27 Chaves CJ, Caplan LR, Chung CS, Tapias J, Amarenco P Teal $\mathrm{P}$, et al. Cerebellar infarcts in the New England Medical Center Posterior Circulation Registry. Neurology 1994;44:1385-90.

28 Trouillas P, Nighoghossian N, Philippon B. Nuclear hemodynamic vertebrobasilar insufficiency. A new approach with the xenon Xe133 method. Arch Neurol 1991;48: 921-9.

29 Bogousslavsky J, Regli F, Uske A. Thalamic infarcts: clinical syndromes, etiology, and prognosis. Neurology 1988;38: 837-48.

30 Mehler MF. A novel basilar artery syndrome with acute confusion and benign outcome. Neurology 1984;34:203.

31 Barkhof F, Valk J. "Top of the basilar" syndrome: a comparison of clinical and MR findings. Neuroradiology 1988;30:293-8.

32 Tettenborn B, Caplan LR, Sloan MA, Estol CJ, Pessin MS, De Witt LO, et al. Postoperative brainstem and cerebellar infarcts. Neurology, 1993;43:471-7.

33 Tettenborn B. Multifocal ischemic brains-stem lesions. In brainstem localization and function. Caplan LR, Hopf HC eds. Berlin: Springer-Verlag, 1994:23-31.

34 Tohgi H, Takahashi S, Chiba K, Hirata Y for the Tohoku Cerebellar Infarction Study Group. Cerebellar infarction: clinical and neuroimaging analysis in 239 patients. Stroke 1993;24;1697-701.

35 Milandre L, Brosset C, Gouirand R, Khalil R. Les infarctus cérébelleux purs: trente observations. Presse Med 1992; 21:1562-5.

36 Macdonell RAL, Kalnis RM, Donnan GA. Cerebella infarction: natural history, prognosis and pathology. Stroke 1989;18:849-55.

37 Orgogozo JM, Bogousslavsky J. Lacunar syndromes. In Vinken PJ, Bruyn GW, Klawans HL, eds. Handbook of clinical neurology. Vol 54. Amsterdam: Elsevier, 1989: 235-69.

38 Nadeau S, Jordan J, Mishra S. Clinical presentation as a guide to early prognosis in vertebrobasilar stroke. Stroke 1992;23:165-70.

39 Hornig CR, Buettner T, Hoffmann O, Dorndorf W. Shortterm prognosis of vertebrobasilar ischemic stroke. term prognosis of vertebro

40 Pessin MS, Gorelick PB, Kwan ES, Caplan LR, Basilar artery stenosis: middle and distal segments. Neurology artery stenosis:

41 Tournier-Lasserve E, Iba-Zizen MT, Romero MT, Bousser MG. Autosomal dominant syndrome with stroke-like episodes and leukoencephalopathy. Strok 1991;22:1297-302.

42 Hankey GJ. Isolated angiitis/angiopathy of the central nervous system. Cerebrovasc Dis 1991;1:2-15.

43 Amarenco P, Roullet E, Goujon C, Cheron F, Haw J-J, Bousser MG. Infarction in the anterior rostral cerebellum territory of the lateral branch of the superior cerebellar artery). Neurology 1991;41:253-8.

44 Caplan L, Tettenborn B. Vertebrobasilar occlusive disease: review of selected aspects. 2. Posterior circulation review of selected aspects. 2. Posterior

45 Pessin MS, Daneault N, Kwan ES, Eisengart MA, Caplan LR. Local embolism from vertebral artery occlusion. Stroke 1988;19:112-5.

46 Caplan LR Vertebrobasilar occlusive disease. In: Barnet HJ, Mohr JP, Stein B,Yatsu F, eds. Stroke: pathophysiology, diagnosis, and management. New York: Churchil Livingstone, 1986:549-619.

47 Amarenco P, Hauw J, Gautier JC. Arterial pathology in cerebellar infarction. Stroke 1990;21:1299-305.

48 Caplan LR. Occlusion of the vertebral or basilar artery. Follow-up analysis of some patients with benign outcome. Stroke 1979;3:277-82.

49 Labauge $R$, Pagès $M$, Blard JM. Survie prolongée après occlusion du tronc basilaire: 4 cas. Rev Neurol 1989; 145:789-94.

50 Ueda $\mathrm{K}$, Toole JF, McHenry LC Carotid and vertebrobasilar transient ischemic attacks: clinical and angiobrobasilar transient ischemic attacks: clinical and

51 Kittner SJ, Sharkness CM, Price TR, Plotnick GD, Dambrosia JM, Wolf PA, et al. Infarcts with a Dambrosia JM, Wolf PA, et al. Infarcts with a
cardiac source of embolism in the NINCIDS Stroke cardiac source of embolism in the NINCIDS Stroke Data Bank: historical features. Neurology 1990;40:281-84. 52 Marshall RS, Mohr JP. Current management of ischa stroke. $\mathcal{F}$ Neurol Neurosurg Psychiatry 1993;56:6-16. MG, Haw J-J. The prevalence of ulcerated plaques in the aortic arch in patients with stroke. $N$ Engl $f \mathrm{Med}$ 1992;326:221-5.

54 Caplan LR, Amarenco P, Rosengart A, Lafranchise EF, Teal PA, Belkin M, et al. Embolism from vertebral artery origin occlusive disease. Neurology 1992;42:1505-12. 